\section{Physiological and Horticultural Effects of Sweet Cherry Chemical Blossom Thinners}

\author{
Olivia M. Lenahan and Matthew D. Whiting ${ }^{1}$ \\ Washington State University, Irrigated Agriculture Research and Extension \\ Center, 24106 N. Bunn Road, Prosser, WA 99350
}

Additional index words. Prunus avium, ammonium thiosulphate (ATS), vegetable oil emulsion (VOE), tergitol, fish oil + lime sulphur (FOLS), fruit set, fruit yield, leaf ontogeny, phytotoxicity, source-sink relations

\begin{abstract}
This article reports on the physiological effects and horticultural benefits of

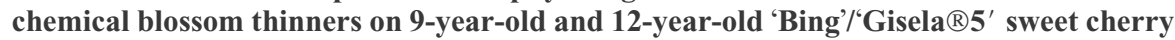
trees in 2004 and 2005, respectively. Chemical thinning agents were applied at $20 \%$ and $80 \%$ full bloom (FB) by air-blast sprayer and were comprised of: $2 \%$ ammonium thiosulphate (ATS), 4\% vegetable oil emulsion (VOE), $2 \%$ fish oil $+2.5 \%$ lime sulfur (FOLS), 1\% tergitol, and an untreated control. Leaf gas exchange, leaf SPAD meter readings, chlorophyll fluorescence parameters, fruit yield, and fruit quality were evaluated. FOLS, tergitol, VOE, and ATS suppressed leaf net $\mathrm{CO}_{2}$ exchange rate (NCER) by $33 \%, 30 \%, 28 \%$, and $18 \%$, respectively, over a variable length recovery period directly after $80 \%$ FB treatment. Leaf NCER recovered fully from every thinning treatment. Reductions in leaf NCER were unrelated to $g_{\mathrm{S}}$. VOE reduced estimated leaf chlorophyll content the greatest, suppressing overall levels by $11 \%$ for 23 days after treatment. All blossom thinners reduced constant fluorescence (Fo). No thinning agent reduced fruit set or yield in 2004 . ATS, FOLS, and tergitol reduced fruit set in 2005 . VOE was ineffective as a thinner yet exhibited significant leaf phytotoxicity. Among thinners, there was no relationship between inhibition of leaf NCER and thinning efficacy.
\end{abstract}

The recent availability of precocious dwarfing rootstocks for sweet cherry (Prunus avium L.) has facilitated the transition to highly efficient orchard systems, especially with respect to labor. Mature 'Bing' trees grown on 'Gisela ${ }^{\circledR 5} 5$ ' $(P$. cerasus $\times P$. canescens) for example, exhibit $\approx 46 \%$ less trunk cross-sectional area than those grown on the industry standard, Mazzard (Whiting et al., 2005). In addition, Gisela rootstocks (e.g., 5, 6 , and 7) typically induce yields of five to seven times higher than those induced by Mazzard (Lang and Ophardt, 2000; Whiting et al., 2005). However, without prudent canopy and crop load management, these potentially advantageous rootstock characteristics can create overproductive orchards that yield small fruit (Whiting and Ophardt, 2005; Whiting et al., 2006). The concomitant reduction in canopy size and increase in crop load have a negative effect on canopy sourcesink relations. Whiting et al. (2005) and Lang

Received for publication 16 May 2006. Accepted for publication 26 June 2006 .

We are grateful to David Ophardt for technical assistance; Dr. James McFerson, Dr. Don Elfving, and Dr. Preston Andrews for their critical manuscript reviews; and to the WSU Agricultural Research Center and the Washington Tree Fruit Research Commission for financial support. The cost of publishing this paper was defrayed in part by the payment of page charges. Under postal regulations, this paper therefore must be hereby marked advertisement solely to indicate this fact. ${ }^{1}$ To whom reprint requests should be addressed; e-mailmdwhiting@wsu.edu. and Ophardt (2000) reported fruit weight was ca. $16 \%$ lower for 'Bing' and 'Rainier' grown on 'Gisela ${ }^{\circledR} 5$ ' and 'Gisela ${ }^{\circledR 7}$ ' rootstocks, respectively, compared with fruit from Mazzard-rooted trees. A close negative relationship between cherry fruit weight and soluble solids and canopy fruit-to-leaf area ratio (F:LA) has been documented (Whiting and Lang, 2004). However, previous research at the Irrigated Agriculture Research and Extension Center in Prosser has modeled the balance between fruit quality and F:LA and shown that high-quality fruit can be grown on precocious and dwarfing rootstocks (Whiting and Lang, 2004; Whiting and Ophardt, 2005). Several practical strategies for achieving balanced cropping targets were reviewed recently (Whiting and Ophardt, 2005). More recently, trials have shown potential for chemically thinning blossoms to balance crop load in high efficiency sweet cherry orchard systems (Whiting et al., 2006).

Chemical thinning is an established management practice for apple (Malus domestica Borkh.) to improve fruit quality and offset biennial bearing patterns. Ammonium thiosulphate (ATS) is a caustic blossom thinner proposed to reduce fruit set through injury to flowers, which prevents fertilization. Byers and Lyons (1985) reported ATS at $50 \mathrm{~mL} \cdot \mathrm{L}^{-1}$ effectively prevented fertilization and fruit set of 'Redhaven' peach ( $P$. persica) when applied directly to the stigma. More recently, Fallahi and Willemsen (2002) showed that ATS applied at $1 \%$ reduced fruit set of 'Delicious' by $30 \%$ and improved fruit weight by $11 \%$. In addition, Bound and Jones (2004) reported significant reductions in fruit set and improvements in 'Delicious' apple fruit weight with applications of $1.5 \%$ ATS at $20 \%$ and $50 \%$ bloom. In peach, Southwick et al. (1996) reported comparably good fruit quality between hand-thinned trees and those chemically thinned with the surfactant Armothin $\AA$. More recently, tergitol (2,6,8-trimethyl-4-nonyloxypolyethyleneoxyethanol) has also shown efficacy as a peach caustic blossom thinning agent (Fallahi, personal communication).

Another putative chemical thinner mode of action is a reduction in spur/canopy carbon balance limiting photosynthate available to developing fruit. The photosynthetic inhibitor, terbacil, as well as postbloom shading have thinned apple and peach fruitlets by reducing canopy net $\mathrm{CO}_{2}$ exchange rate (NCER) (Byers et al., 1985). Byers et al. (1990) found that shading apple trees for a 10 -d period shortly after bloom reduced leaf NCER by $67 \%$, resulting in fruit abscission. In addition, terbacil applied postbloom reduced NCER by ca. $90 \%$ on the third d after treatment, reduced fruit set, and improved size of remaining fruit. McArtney et al. (2004) reported successfully thinning 'Royal Gala' apples with a combination of lime sulfur applications and shade treatment 35 to $38 \mathrm{~d}$ after bloom.

Apple fruit abscission is also induced by hormonal thinners. For example, naphthaleneacetic acid (NAA), an auxin fruit thinner, is typically applied to apple trees 2 weeks after bloom and thins fruit by reducing assimilation and translocation of carbohydrate resources from the leaves to the fruit thereby inducing pedicle-spur abscission zone development (Schneider, 1978; Stopar et al., 1997). Benzyladenine (BA) has also successfully thinned and improved apple fruit quality (Elfving, 1989). In addition, Yuan and Greene (2000) reported a reduction $(\approx 11 \%)$ in photosynthesis after BA application and suggested that this response combined with an increase in dark respiration is responsible for thinning.

Ongoing trials at Washington State Univ. are studying the physiological effects and horticultural benefits of a number of chemical blossom thinners on sweet cherry trees. ATS, fish oil + lime sulfur (FOLS), and tergitol have consistently reduced 'Bing' fruit set and improved fruit quality compared with the unthinned control (Whiting et al., 2006). However, to date, there are no reports on the physiological effect of these blossom thinners. Understanding thinner effects and mode of action may be helpful in developing more effective thinning programs. The objectives of this study were severalfold: 1) to evaluate the efficacy and horticultural effects of chemical blossom thinners on mature 'Bing'/“Gisela ${ }^{\circledR} 5$ ' sweet cherry trees; and 2) to evaluate the effect of chemical thinners on sweet cherry leaf physiology (photosynthesis, chlorophyll fluorescence, and leaf chlorophyll content) to better understand thinner mode of action. 


\section{Materials and Methods}

Plant material and experimental design. All trials were conducted in 2004 and 2005 at Washington State University's Roza experimental farm in Prosser, Wash. $\left(46.2^{\circ} \mathrm{N}\right.$, $\left.119.7^{\circ} \mathrm{W}\right)$. Treatments were imposed on 9- (2004) and 12-year-old (2005) 'Bing'/ 'Gisela ${ }^{\circledR 5}$ ' sweet cherry trees planted in North-South rows and spaced $2.5 \times 5.0 \mathrm{~m}$. Trees were irrigated with under-tree lowvolume microsprinklers from bloom to leaf senescence. Typical orchard management strategies (e.g., dormant pruning, fertilization, pesticide application) were carried out both seasons.

In both years, the experiments were arranged in a completely randomized design and consisted of 25 'Bing' trees of similar vigor with five single-tree replications per treatment. Treatment means were compared by Duncan's test at 0.05 and 0.10 per measurement day and over leaf recovery periods by analysis of variance (Proc GLM) using the statistical analysis system (SAS) program (SAS Institute, Cary, N.C.).

Chemical blossom-thinning trial. Chemical thinning agents were applied in the morning (between 8:00 and 10:00 HR) at ca. 20\% and $80 \%$ full bloom (FB) (5 Apr. and $8 \mathrm{Apr}$. 2004 and 3 Apr. and 7 Apr. 2005) to whole trees with a standard orchard air blast sprayer $(200 \mathrm{gal} / \mathrm{ac})$ and were comprised of: $2 \%(\mathrm{v} / \mathrm{v})$ ATS, 4\% vegetable oil (soy bean) emulsion (VOE), $2 \%$ fish oil $+2.5 \%$ lime sulfur (FOLS), $1 \%$ tergitol, and an untreated control.

Leaf net $\mathrm{CO}_{2}$ exchange rate (NCER), $g_{\mathrm{S}}$ $\left(\mathrm{g}_{\mathrm{s}}\right)$ and intercellular $\mathrm{CO}_{2}\left(\mathrm{C}_{\mathrm{i}}\right)$ were measured in situ on three sunlit fruiting spur leaves (24-year-old) per tree within $1 \mathrm{~h}$ of solar noon (12:00 HR to 14:00 HR). Measurements were conducted with a portable IR $\mathrm{CO}_{2}$ gas analyzer (CIRAS-2; PP Systems, Haverhill, Mass.) equipped with a tungsten halogen lamp set to saturating irradiance (1000 $\left.\mu \mathrm{mol} \cdot \mathrm{m}^{-2} \cdot \mathrm{s}^{-1} P A R[\mathrm{PAR}]\right)$ with reference (inlet) $\left[\mathrm{CO}_{2}\right]$ of $\approx 370 \mathrm{ppm}$ and leaf temperature between 25 to $30^{\circ} \mathrm{C}$. In 2004 , measurements were taken between DOY 145 and DOY 258 (25 May and 14 Sept.) at a weekly interval. In 2005, measurements were collected within $4 \mathrm{~h}$ after the $80 \%$ FB treatment and every 2 to $3 \mathrm{~d}$ until NCER values in all treatments were statistically similar $(P<$ 0.05 ) to the untreated control.

On the same leaves measured for gas exchange, chlorophyll fluorescence was measured in 2005 with a portable pulse-modulated fluorometer (FMS-2; Hansatech Instruments, Ltd., U.K.). Quantum efficiency of photosystem II ( $\phi$ PSII) and photochemical quenching $(\mathrm{qP})$ were obtained by a saturating light pulse $\left(18,000 \mu \mathrm{mol} \cdot \mathrm{m}^{-2} \cdot \mathrm{s}^{-1}\right)$ followed by a far-red light pulse $(735 \mathrm{~nm})$. To determine initial fluorescence (Fo), leaves were darkadapted for $15 \mathrm{~min}$ and then exposed to a modulating beam. Fv was calculated as Fo - Fm. The efficiency of photosystem II and $\mathrm{qP}$ were calculated by the following standard equations (Hansatech Instruments, Ltd.): (Fm'-Fs)/Fm'; (Fm'-Fs)/(Fm'-Fo).
Leaf chlorophyll content was estimated with a portable meter (SPAD-502; Minolta, Japan). Measurements in 2004 were made throughout the season until early leaf senescence. In 2005, SPAD readings were taken directly after the $80 \%$ FB thinning application until recovery of leaf NCER. In both years, measurements were conducted on fruiting spur leaves in situ in the middle of the leaf, avoiding the midrib. Individual leaf surface area $(\mathrm{n}=20)$ was measured using a portable laser scanning area meter (CI-203; CID Inc., Camas, Wash.)

Air temperature (at $1 \mathrm{~m}$ ), relative humidity, solar radiation, and wind speed were recorded within $500 \mathrm{~m}$ of the experimental orchard by a WSU Public Agricultural Weather System (PAWS) weather station.

Fruit set, quality, and yield. Fruit set (percent available flowers) was determined by comparing number of flowers (minimum 100 flowers, mean $\pm \mathrm{SD}=133 \pm 13$ ) at $\mathrm{FB}$ on one east- and one west-facing branch (2-3year-old) per tree with the number of fruit on the same branches just before harvest. Whole tree yields were recorded at harvest (15 June 2004 and 24 June 2005). Fruit quality [firmness and diameter (Firmtech2, BioWorks, Inc., Wamego, Kan.), soluble solids digital refractometer, (Atago Co., Ltd., Japan)], and weight were determined at room temperature within $24 \mathrm{~h}$ of harvest from 100-fruit subsamples per tree.

\section{Results and Discussion}

Leaf gas exchange. Single leaf NCER was reduced significantly by every thinning treatment (Fig. 1A, B; Table 1), although the degree and duration of inhibition varied among treatments by ca. twofold. Leaf recovery was considered the period between application and the sample date at which NCER of treated leaves was statistically similar $(P<0.05)$ to those of untreated leaves. Within $4 \mathrm{~h}$ of the $80 \% \mathrm{FB}$ application in 2005, VOE, ATS, FOLS, and tergitol had reduced NCER by $32 \%, 44 \%, 59 \%$, and $64 \%$, respectively, compared with the control. Leaves treated with ATS recovered first, after $\approx 7 \mathrm{~d}$. In contrast, on the same date, leaf NCER of VOE-, FOLS-, and tergitol-treated trees was still $24 \%, 40 \%$, and $35 \%$, lower than the control, respectively. VOE-treated leaves showed recovery of NCER by $\approx 14$ $\mathrm{d}$ after application and FOLS- and tergitoltreated leaves showed recovery by $17 \mathrm{~d}$ after application (Fig. 1A). Mean midday NCER throughout the variable-length recovery period for ATS, VOE, tergitol, and FOLS was $82 \%, 72 \%, 71 \%$, and $67 \%$ of the untreated control, respectively. Therefore, ATS was the least inhibiting to leaf NCER, effecting only a slight reduction in NCER, from which leaves recovered relatively quickly. The other thinners acted similarly in the extent and duration of their reduction of leaf NCER (Table 1).

Bound and Jones (2004) reported slight leaf marginal damage from $1.5 \%$ ATS ap- plied to apple and pear (Pyrus communis L.) trees during bloom and severe leaf desiccation and bud death from applications of $4 \%$ ATS. In the current trial, $2 \%$ ATS caused no visible symptoms of damage to leaves. Ju et al. (2001) reported that full bloom applications of up to $5 \%$ corn oil emulsion to 'Bing' had no effect on photosynthesis. In contrast, in the current trial, we documented $32 \%$ inhibition of leaf NCER immediately after VOE application, which was not recovered from for $14 \mathrm{~d}$. Discrepancies may be related to properties of soy bean versus corn oil emulsions, application timing (prebloom vs. $80 \%$ FB), as well as weather conditions at the time of application. Importantly and irrespective of thinner, leaves exhibited full recovery. We documented a similar response in 2004 and found no differences in leaf NCER among treatments beyond 14 to 17 d (data not shown). Moreover, we recorded no compensatory increase in leaf NCER throughout the growing season. We hypothesize that transient inhibition of leaf NCER will be an important characteristic of any thinning program because maximum leaf assimilation rates will be critical during stage III of fruit development as fruit attain final size. In addition, the capacity for NCER (i.e., individual leaf surface area) was unaffected by thinning agents applied during bloom and concomitant leaf expansion (data not shown). This is also important for maximizing leaf assimilate supply as discussed previously.

We reported previously that NCER of leaves treated with FOLS 14 d after FB was reduced by $26 \%$ within $24 \mathrm{~h}$ of treatment and by $19 \%$ overall, a reduction that took leaves $7 \mathrm{~d}$ to recover from (Lenahan and Whiting, 2006). In contrast, leaves treated during bloom exhibited a mean NCER reduction of $33 \%$ over a $17-d$ recovery period. In addition, less-developed leaves $\left(\approx 20 \mathrm{~cm}^{2}\right)$ treated with FOLS showed slight leaf marginal desiccations whereas postbloom treated leaves $(\approx 51$ $\mathrm{cm}^{2}$ ) showed no visible signs of damage. These results suggest that leaves become less susceptible to damage with maturity, although postbloom applications of FOLS were made only once versus two applications during bloom and environmental conditions varied among application dates. Indeed, Bukovac et al. (1979) reported a reduction in leaf cuticle permeability and aqueous solution retention in peach concomitant with leaf development. However, relative humidity $(\mathrm{RH})$ during the bloom applications $(\mathrm{RH}=$ $64 \%$ and $74 \%$ ) favored chemical absorption over the drier conditions during the postbloom application $(\mathrm{RH}=39 \%)$. Bukovac (1973) reported that high humidity increases the drying time and wetness of the leaf cuticle-factors that prolong the presence of the treatment on the leaf, thereby damaging leaf tissue.

$G_{\mathrm{S}}\left(\mathrm{g}_{\mathrm{s}}\right)$ did not respond similarly to all thinning treatments. FOLS reduced overall $g_{s}$ (throughout the NCER recovery period) by $17 \%$, compared with the control. In contrast bloom applications of ATS, VOE, and tergitol were less caustic, reducing overall $g_{s}$ by 
$11 \%, 8 \%$, and $12 \%$, respectively (Table 1 , Fig. 1C, D). This suggests that FOLS may affect NCER differently from other thinners and that stomatal closure is involved in the NCER reduction from FOLS. Interestingly, leaf intercellular $\mathrm{CO}_{2}\left(\mathrm{C}_{\mathrm{i}}\right)$ from the VOE, tergitol, and FOLS blossom-thinning treatments was higher than the control on each measurement day for $14 \mathrm{~d}$ (Fig. 1E); and the overall $\mathrm{C}_{\mathrm{i}}$ mean from throughout the recovery period was significantly higher than the control by $18 \%, 17 \%$, and $20 \%$, respectively (Table 1). The concomitant increase in $\mathrm{C}_{\mathrm{i}}$ and reduction in NCER is indicative of stress and suggests that these thinners induce a nonstomatal limitation to NCER (Farquhar and Sharkey, 1982). This hypothesis is supported by the weak correlation $\left(r^{2}=0.06-0.19\right)$ between NCER and $g_{s}$ that we discovered.

These results suggest that young, emerging leaves are more susceptible to photosynthetic inhibition by thinning agents than mature leaves. Similarly, Stopar et al. (1997) found that inhibition of apple leaf NCER by NAA varied with leaf ontogeny and was more sensitive at early stages. This is likely the result of incomplete development of photosynthetic competency, immature stomates in young leaves (Sams and Flore, 1982), and greater absorption of the thinners. There was no consistent negative effect of any treatments on the seasonal trend of leaf NCER (data not shown). All leaves followed the typical seasonal pattern of increasing NCER and $g_{s}$ with leaf age and sink demand peaking near harvest and declining thereafter (Whiting and Lang, 2004).

Chlorophyll fluorescence. Chlorophyll fluorescence measurements are useful for better understanding the functioning of the photosynthetic machinery, particularly photosystem II (Krause and Weis, 1984). Changes in chlorophyll fluorescence have been associated with physiological stresses, including drought (Souza et al., 2004) and cold shock (Pietrini et al., 2005), for example. In the current trial, several components of leaf chlorophyll fluorescence were affected by thinners (Table 1), although we found no consistent response among treatments. Constant fluorescence $(\mathrm{Fo})$, the fluorescence yield after dark adaptation (i.e., photosystem II reaction centers are open), was reduced $12 \%$ by ATS and $9 \%$ by FOLS. These results suggest thinners damaged the light-harvesting complex and increased energy dissipation through nonphotochemical processes (Percival and Henderson, 2002; Pietrini et al., 2005). Similar reductions in Fo have been reported for several tree species in response to foliar applications of salt (Percival and Henderson, 2002).

Variable fluorescence $(\mathrm{Fv})$, the difference between maximal fluorescence and constant fluorescence, is indicative of the quenching rate of the photosystem II electron acceptor. VOE, tergitol, and FOLS reduced Fv similarly and by ca. $15 \%$ (Table 1). This suggests that reductions in NCER from VOE, tergitol, and FOLS were caused, in part, from damage to the thylakoid membrane (Krause and

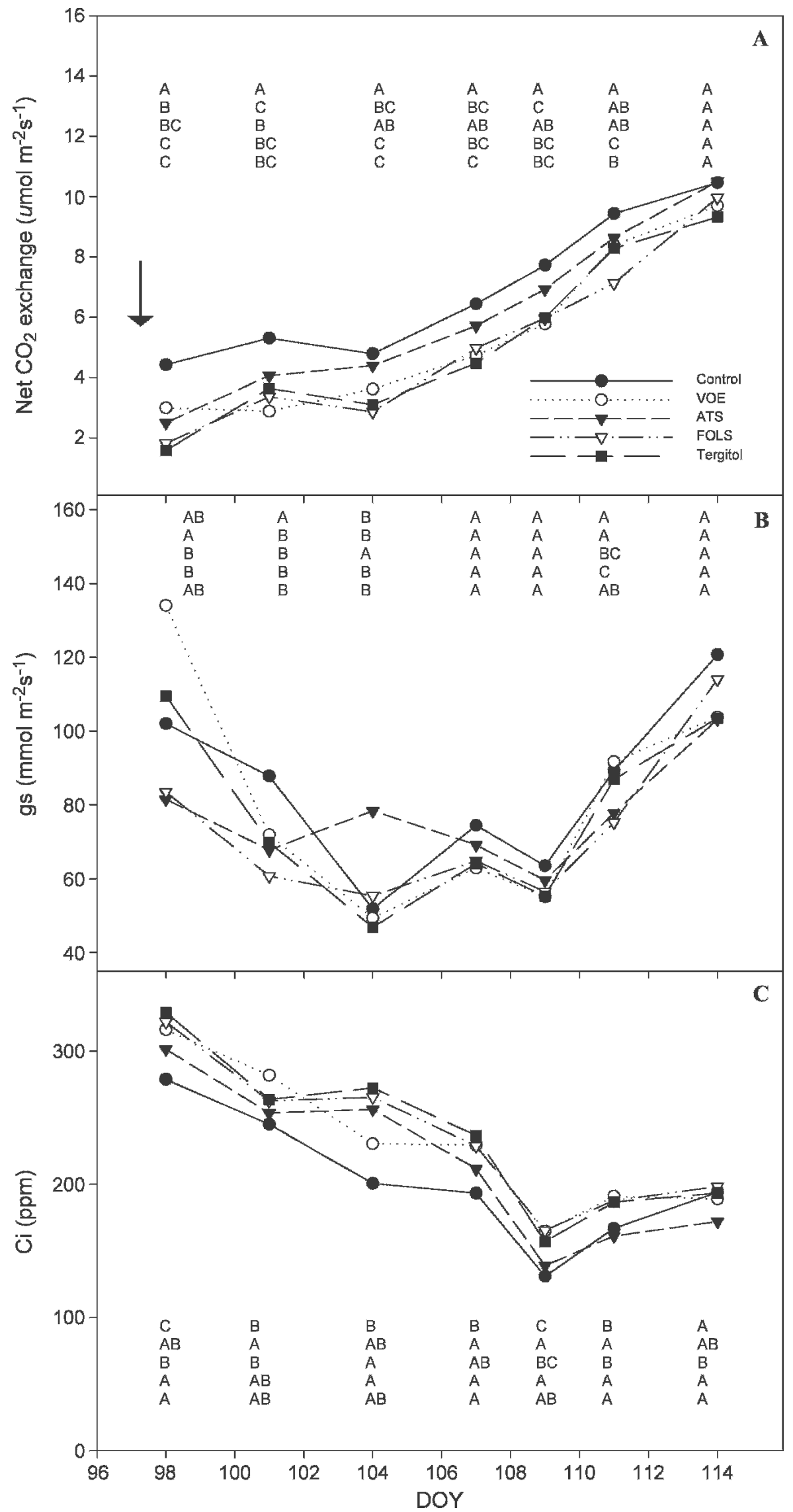

Fig. 1. Effect of chemical blossom thinners on (A) leaf net $\mathrm{CO}_{2}$ exchange rate, (B) $g_{\mathrm{S}}$, and (C) intercellular $\mathrm{CO}_{2}$ of 12 -year-old 'Bing'/'Gisela ${ }^{\circledR} 5^{\prime}$ ' sweet cherry trees in 2005 . Letters indicate statistical differences by Duncan analysis of variance test $(\mathrm{n}=5, P=0.05)$. Order of the statistical comparisons corresponds to the following treatments: control, VOE, ATS, FOLS, and tergitol. Arrow indicates $80 \%$ full bloom application (DOY 97). 
Weis, 1984). In contrast, ATS had no effect on $\mathrm{Fv}$, further evidence that it possesses a distinct mode of action.

No thinning agent affected the quantum efficiency of photosystem II (ФPSII) or photochemical quenching (qP). However, ФPSII and qP of untreated leaves increased by $34 \%$ and $19 \%$, respectively, from first emergence to ca. $20 \mathrm{~d}$ later (Table 1). This is likely the result of changes in photosynthetic competency during leaf development and maturation. Greer (1995) reported a seasonal increase in the efficiency of photosystem II in kiwi fruit and found that photosynthetic competency was positively related with chlorophyll development and leaf expansion. Similar seasonal increases in $\mathrm{qP}$ and photochemical efficiency have been reported in apple (Greer et al., 1997).

Chlorophyll content. Leaf chlorophyll content has been positively correlated with SPAD units in coffee (Coffea canephora) leaves (Netto et al., 2005), Benjamin fig (Ficus benjamina) and Cottonwood (Populus deltoides) trees (Loh et al., 2002), and peach leaves (Shi and Byrne, 1995). Moreover, total leaf chlorophyll concentration per unit fresh weight in greenhouse grown sweet cherry was closely, positively, and linearly correlated with SPAD units $\left(\mathrm{r}^{2}=0.88\right)$ (Lenahan, 2005). In the current trial, all thinning treatments reduced SPAD units and therefore leaf chlorophyll (data not shown). Three days after $80 \%$ FB applications, leaf chlorophyll was $19 \%, 18 \%, 12 \%$, and $6 \%$ lower than the control for ATS, tergitol, FOLS, and VOE, respectively. ATS-treated leaves recovered the soonest, after $\approx 7 \mathrm{~d}$, creating an overall reduction of $13 \%$. Leaves treated with FOLS and tergitol showed mean reductions of $15 \%$ and $17 \%$, respectively, over $18 \mathrm{~d}$. VOE reduced estimated leaf chlorophyll the longest, suppressing content by an average of $11 \%$ over $\approx 23 \mathrm{~d}$ after the $80 \%$ FB application. The trend of increasing SPAD levels from bloom onward parallels the increase in leaf NCER (data not shown). Moreover, we have found a strong correlation between NCER and SPAD units $\left(r^{2}=0.92\right)$ from leaf emergence to ca. $14 \mathrm{~d}$ after FB (data not shown), supporting previous research on cherry that chlorophyll content is the limiting factor in photosynthesis of young leaves (Roper and Kennedy, 1986).

\section{Yield and Fruit Quality}

Blossom thinners in 2004. No chemical blossom thinner had any beneficial effect on fruit set or yield in 2004. Fruit weight, soluble solids, and firmness were similar among all treatments and poor (Table 2). Overall, fruit set was high at $54 \%$. This is likely related to favorable pollination conditions-little wind and warm day and night temperatures (data not shown). In addition, the experimental orchard had a high pollenizer density (33\%). Despite there being no yield differences, there were differences in mean fruit diameter (in millimeters) among treatments. The greatest percent of fruit from FOLS-
Table 1. Overall effect of chemical blossom thinners (applied $20 \%$ and $80 \%$ full bloom) on sweet cherry leaf gas exchange, $g_{\mathrm{S}}$, intercellular $\mathrm{CO}_{2}$ and fluorescence. ${ }^{\mathrm{z}}$

\begin{tabular}{lccccccc}
\hline $\begin{array}{l}\text { Thinning } \\
\text { treatment }\end{array}$ & $\begin{array}{c}\text { NCER } \\
\left(\mu \mathrm{mol} \cdot \mathrm{m}^{-2} \cdot \mathrm{s}^{-1}\right)\end{array}$ & $\begin{array}{c}\mathrm{g}_{\mathrm{s}} \\
\left(\mathrm{mmol} \cdot \mathrm{m}^{-2} \cdot \mathrm{s}^{-1}\right)\end{array}$ & $\begin{array}{c}\mathrm{C}_{\mathrm{i}} \\
(\mathrm{ppm})\end{array}$ & Fo & Fv & ФPSII & \multicolumn{1}{c}{$\mathrm{qP}$} \\
\hline Control & $7.0 \mathrm{a}$ & $82.9 \mathrm{a}$ & $197 \mathrm{~b}$ & $384 \mathrm{a}$ & $1239.8 \mathrm{a}$ & $0.5055^{\mathrm{NS}}$ & $0.765^{\mathrm{NS}}$ \\
VOE & $5.1 \mathrm{bc}$ & $75.8 \mathrm{ab}$ & $234 \mathrm{a}$ & $379 \mathrm{ab}$ & $1064.1 \mathrm{~b}$ & 0.514 & 0.764 \\
ATS & $5.9 \mathrm{~b}$ & $73.4 \mathrm{ab}$ & $215 \mathrm{ab}$ & $339 \mathrm{c}$ & $1215.8 \mathrm{a}$ & 0.513 & 0.752 \\
FOLS & $4.7 \mathrm{c}$ & $68.5 \mathrm{~b}$ & $238 \mathrm{a}$ & $347 \mathrm{bc}$ & $1050.9 \mathrm{~b}$ & 0.456 & 0.686 \\
Tergitol & $5.0 \mathrm{bc}$ & $73.6 \mathrm{ab}$ & $230 \mathrm{a}$ & $361 \mathrm{abc}$ & $1054.9 \mathrm{~b}$ & 0.490 & 0.782 \\
$P$ & $<0.0001$ & 0.02 & $<0.0001$ & 0.03 & 0.07 & 0.65 & 0.34 \\
\hline
\end{tabular}

${ }^{2}$ Data are means from immediately after $80 \%$ full bloom thinner application until leaf recovery. Letters indicate statistical differences by Duncan analysis of variance test $(\mathrm{n}=5, P<0.05)$. Means followed by the same letter are not significantly different within a column.

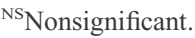

treated trees were $\approx 24.2 \mathrm{~mm}(23.2 \%)$, whereas fruit from ATS- and tergitol-treated trees peaked at $21.4 \mathrm{~mm}$, not a premium fruit size category but still saleable on the fresh market. Crop value was determined from the current pricing structure for fresh market quality fruit, based on fruit diameter, and yield per size category. In general, higher prices are paid for larger diameter fruit and those smaller than $21.5 \mathrm{~mm}$ (12-row) diameter are not saleable on the fresh market. FOLS-, ATS- and tergitol-treated trees had the highest crop values (\$19.7-23.3/tree). In contrast, crop value from untreated control trees was $\approx \$ 10$ less. Crop value from VOEtreated trees was the lowest at $\$ 10.3 /$ tree (ca. $25 \%$ lower than control trees). VOE-treated trees bore the lowest value crop because of low yields of poor quality fruit. Poor fruit quality from VOE-treated trees agrees with a previous report (Whiting et al., 2006).

Blossom thinners in 2005. Thinning agents had variable effects on fruit set, yield, and fruit quality in 2005 (Table 3). Tergitol, ATS, and FOLS significantly reduced fruit set by $52 \%, 44 \%$, and $38 \%$, respectively, compared with the untreated control. In contrast, fruit set was unaffected by VOE. These results are consistent with previous thinner evaluations (Whiting et al., 2006). In addition, VOE has been similarly ineffective at reducing fruit set of other varieties, including 'Lapins' and 'Rainier' (Whiting, unpublished data). In contrast, Ju et al. (2001) reported prebloom, $20 \%$, and $50 \%$ FB applications of corn oil emulsion reduced 'Bing' fruit set and improved weight and soluble solids. Discrepancies are likely related to application timing and possibly to the different vegetable oils (soy oil in the current trial vs. corn). Recent apple blossom thinning research has found differences in thinning efficacy with different oil emulsions applied at similar stages of bloom (J. Schupp, personal communication).

In the current trial, fruit yields were statistically similar, although numerically lower for all thinning treatments (as much as $40 \%$ lower for FOLS). Thinners had no effect on fruit weight. However, tergitol, ATS, and FOLS increased soluble solids and firmness similarly and by ca. $10 \%$ and $15 \%$, respectively.
Table 2. Effect of chemical blossom thinners (applied 5 Apr. and 8 Apr. 2004) on fruit set, fruit yield, fruit quality (soluble solids, weight, firmness), and crop value of 9-year-old 'Bing'/‘Gisela®5' sweet cherry trees in 2004. ${ }^{\mathrm{z}}$

\begin{tabular}{lccclcc}
\hline Treatment & Fruit set $(\%)$ & Yield $(\mathrm{kg})$ & $\begin{array}{c}\text { Soluble Solids } \\
(\%)\end{array}$ & Wt $(\mathrm{g})$ & $\begin{array}{c}\text { Firmness } \\
(\mathrm{g} / \mathrm{mm})\end{array}$ & $\begin{array}{c}\text { Crop value } \\
(\$ / \text { tree })\end{array}$ \\
\hline Control & $4^{\mathrm{NS}}$ & $16.6^{\mathrm{NS}}$ & $16.5^{\mathrm{NS}}$ & $4.7^{\mathrm{NS}}$ & $277.9^{\mathrm{NS}}$ & 13.70 \\
VOE & 58.6 & 15.7 & 15.7 & 4.7 & 272.9 & 10.32 \\
ATS & 60.6 & 19.1 & 15.7 & 5.3 & 282.8 & 23.10 \\
FOLS & 54.4 & 18.7 & 16.4 & 5.4 & 283.5 & 23.32 \\
Tergitol & 50.5 & 14.4 & 16.8 & 5.3 & 264.6 & 19.70 \\
$P$ & 0.66 & 0.33 & 0.27 & 0.48 & 0.16 & \\
\hline
\end{tabular}

zThere were no statistical differences among means $(\mathrm{n}=5, P<0.10)$.

${ }^{\mathrm{NS}}$ Nonsignificant

Table 3. Effect of chemical blossom thinners (3 Apr. and 7 Apr. 2005) on fruit set, fruit yield, fruit quality (soluble solids, weight, firmness), and crop value of 12-year-old 'Bing'/'Gisela ${ }^{\circledR 5}$ ' sweet cherry trees in $2005 .^{\mathrm{z}}$

\begin{tabular}{lcccccc}
\hline Treatment & Fruit set $(\%)$ & Yield $(\mathrm{kg})$ & $\begin{array}{c}\text { Soluble Solids } \\
(\%)\end{array}$ & Wt $(\mathrm{g})$ & $\begin{array}{c}\text { Firmness } \\
(\mathrm{g} / \mathrm{mm})\end{array}$ & $\begin{array}{c}\text { Crop value } \\
(\$ / \text { tree })\end{array}$ \\
\hline Control & $43.2 \mathrm{a}$ & $12.4^{\mathrm{NS}}$ & $22.4 \mathrm{~b}$ & 10.0 & $305.3 \mathrm{c}$ & 37.79 \\
VOE & $44.5 \mathrm{a}$ & 9.8 & $23.0 \mathrm{~b}$ & 9.9 & $316.9 \mathrm{bc}$ & 32.39 \\
ATS & $24.1 \mathrm{~b}$ & 8.2 & $24.7 \mathrm{a}$ & 9.7 & $358.2 \mathrm{a}$ & 26.93 \\
FOLS & $26.9 \mathrm{~b}$ & 7.5 & $24.5 \mathrm{a}$ & 9.6 & $352.5 \mathrm{ab}$ & 24.28 \\
Tergitol & $20.7 \mathrm{~b}$ & 8.5 & $24.5 \mathrm{a}$ & 9.8 & $347.9 \mathrm{ab}$ & 28.31 \\
$P$ & 0.002 & 0.26 & $<0.0001$ & 0.738 & 0.004 &
\end{tabular}

${ }^{\mathrm{z}}$ Letters indicate statistical differences by Duncan analysis of variance test $(n=5)$. Means followed by the same letter are not significantly different within a column.

${ }^{\mathrm{NS}}$ Nonsignificant. 
Unlike 2004, fruit from untreated control trees had the highest crop value in 2005 (Table 3). This was the result of higher yields from control trees rather than differences in fruit quality; fruit firmness and soluble solids content are not considered for determining crop value. Despite fruit set reductions from ATS, FOLS, and tergitol, fruit weight was not improved on and thus did not compensate for reduced yield. This is likely because of low yields in 2005 and overthinning. We hypothesize that because fruit size was not improved on with ca. 50\% reductions in fruit set (and presumably, fruit number per tree), fruit on unthinned control trees were not limited in their growth by carbohydrate resources (i.e., fruit growth was not source-limited). In this scenario, fruit thinning is unnecessary. This highlights the potential importance of evaluating fruit set before imposing any thinning strategy. To this end, we have recently evaluated the potential for thinning fruitlets postbloom with FOLS (Lenahan and Whiting, 2006).

In conclusion, chemical blossom thinning agents ATS, FOLS, and tergitol show promise as crop load management tools for productive sweet cherry orchards. The relationships between fruit set and physiological impact of thinners presented here provide insight into possible thinning modes of action. Among the thinners evaluated here, multiple modes of action appear to be involved. We report no clear relationship between inhibition of leaf NCER and thinning efficacy among thinners. For example, ATS reduced significantly fruit set despite being the least damaging thinner to leaf carbon balance, chlorophyll content, and thylakoid membrane structure (Fv). These results suggest that ATS thins through causticity to floral parts and preventing pollination. Moreover, VOE was similar in its reduction of leaf NCER to FOLS and tergitol yet elicited no thinning. In contrast, FOLS and tergitol significantly reduced fruit set and strongly inhibited NCER, reduced leaf chlorophyll, and damaged components of the photosynthetic machinery. A combination of causticity to floral parts and reductions in leaf carbon balance is the likely thinning mode of action. Current research in our laboratory is investigating the relative contributions of each mode of action. Further research into the mechanisms and efficacy of chemical thinners will be helpful for developing improved and effective crop load management strategies in high-efficiency sweet cherry orchard systems.

\section{REFERENCES}

Bound, S.A. and K.M. Jones. 2004. Ammonium thiosulphate as a blossom thinner of 'Delicious' apple, 'Winter Cole' pear and 'Hunter' apricot. Austral. J. Expt. Agr. 44:931-937.

Bukovac, M.J. 1973. Foliar penetration of plant growth substances with special reference to tree fruits. Acta Hort. 34:69-78.

Bukovac, M.J., J.A. Flore, and E.A. Baker. 1979. Peach leaf surfaces: Changes in wettability, retention, cuticular permeability, and epicuticular wax chemistry during expansion with special reference to spray application. J. Amer. Soc. Hort. Sci. 104:611-617.

Byers, R.E., J.A. Barden, R.F. Polomski, R.W. Young, and D.H. Carbaugh. 1990. Apple thinning by photosynthetic inhibition. J. Amer. Soc. Hort. Sci. 115:14-19.

Byers, R.E. and C.G. Lyons. 1985. Peach flower thinning and possible sites of action of desiccating chemicals. J. Amer. Soc. Hort. Sci. 110:662-667.

Byers, R.E., C.G. Lyons, and K.S. Yoder. 1985. Peach and apple thinning by shading and photosynthetic inhibition. J. Hort. Sci. 60:465-472.

Elfving, D.C. 1989. N-(phenylmethyl)-1H-purine6-amine (BA) as a chemical thinner for 'Idared' apple. Acta Hort. 239:357-362.

Fallahi, E. and K.M. Willemsen. 2002. Blossom thinning of pome and stone fruit. HortScience 37:474-477.

Farquhar, G.D. and T.D. Sharkey. 1982. Stomata conductance and photosynthesis. Annu. Rev. Plant Physiol. 33:317-345.

Greer, D.H. 1995. Effect of canopy position on the susceptibility of kiwifruit (Actinidia deliciosa) leaves on vines in an orchard environment to photoinhibition throughout the growing season. Aust. J. Plant Physiol. 22:299-309.

Greer, D.H., J.N. Wunsche, and J.W. Palmer. 1997 Effects of fruiting on seasonal apple leaf chlorophyll fluorescence. Acta Hort. 451:345-350.

Ju, Z., Y. Duan, Z. Ju, and A. Guo. 2001. Corn oil emulsion for early bloom thinning of trees of 'Delicious' apple, 'Feng Huang' peach, and 'Bing' cherry. J. Hort. Sci. Biotechnol. 76: 327-331.

Krause, G.H. and E. Weis. 1984. Chlorophyll fluorescence as a tool in plant physiology. II. Interpretation of fluorescence signals. Photosyn. Res. 5:139-157.

Lang, G.A. and D. Ophardt. 2000. Intensive crop regulation strategies in sweet cherries. Acta Hort. 514:227-233.

Lenahan, O.M. 2005. Crop load manipulation in sweet cherry: physiological effects and horticultural benefits of chemical thinners and gibberellic acid. Master Thesis.Wash. State Univ., Pullman.

Lenahan, O.M. and M.D. Whiting. 2006. Fish oil plus lime sulphur shows potential as a sweet cherry post-bloom thinning agent. HortScience 41:860-861.

Loh, F.C.W., J.C. Grabosky, and N.L. Bassuk. 2002. Using the SPAD 502 meter to assess chlorophyll and nitrogen content of Benjamin fig and cottonwood leaves. HortTechnology. 12:682-686.

McArtney, S., M. White, I. Latter, and J. Campbell. 2004. Individual and combined effects of shading and thinning chemicals on abscission and dry-matter accumulation of 'Royal Gala' apple fruit. J. Hort. Sci. Biotechnol. 79:441-448.

Netto, A.T., E. Campostrini, J.G. de Oliveira, and R.E. Bressan-Smith. 2005. Photosynthetic pigments, nitrogen, chlorophyll $a$ fluorescence and SPAD-502 readings in coffee leaves. Scientia Hort. 104:199-209.

Percival, G.C. and A. Henderson. 2002. The influence of de-icing salts on growth and leaf photochemistry of seven urban tree species. The Arboricultural J. 26:23-41.

Pietrini, F., D. Chaudhuri, A.P. Thapliyal, and A. Massacci. 2005. Analysis of chlorophyll fluorescence transients in mandarin leaves during a photo-oxidative cold shock and recovery. Agr. Ecosystems and Environ. 106:189-198.

Roper, T.R. and J.A. Kennedy. 1986. Photosynthetic characteristics during leaf development in 'Bing' sweet cherry. J. Amer. Soc. Hort. Sci. 111:938-941.

Sams, C.E. and J.A. Flore. 1982. The influence of age, position, and environmental variables on net photosynthetic rate of sour cherry leaves. J. Amer. Soc. Hort. Sci. 107:339-344.

Schneider, G.W. 1978. Abscission mechanism studies with apple fruitlets. J. Amer. Soc. Hort. Sci. 103:455-458.

Shi, Y. and D.H. Byrne. 1995. Tolerance of Prunus rootstocks to potassium carbonate-induced chlorosis. J. Amer. Soc. Hort. Sci. 120:283-285.

Southwick, S.M., K.G. Weis, and J.T. Yeager. 1996. Bloom thinning 'Loadel' cling peach with a surfactant. J. Amer. Soc. Hort. Sci. 121: 334-338.

Souza, R.P., E.C. Machado, J.A.B. Silva, A.M.M.A. Lagoa, and J.A.G. Silveira. 2004. Photosynthetic gas exchange, chlorophyll fluorescence and some associated metabolic changes in cowpea (Vigna unguiculata) during water stress and recovery. Environ. Exp. Bot. $51: 45-56$.

Stopar, M., B.L. Black, and M.J. Bukovac. 1997. The effect of NAA and BA on carbon dioxide assimilation by shoot leaves of spur-type 'Delicious' and 'Empire' apple trees. J. Amer. Soc. Hort. Sci. 122:837-840.

Whiting, M.D., G. Lang, and D. Ophardt. 2005. Rootstock and training system affect sweet cherry growth, yield, and fruit quality. HortScience 40:582-586.

Whiting, M.D. and G.A. Lang. 2004. 'Bing' sweet cherry on the dwarfing rootstock 'Gisela 5': Thinning affects fruit quality and vegetative growth but not net $\mathrm{CO}_{2}$ exchange. J. Amer. Soc. Hort. Sci. 129:407-415.

Whiting, M.D. and D. Ophardt. 2005. Comparing novel sweet cherry crop load management strategies. HortScience 40:1271-1275.

Whiting, M.D., D. Ophardt, and J.R. McFerson. 2006. Chemical blossom thinners vary in their effect on sweet cherry fruit set, yield, fruit quality, and crop value. HortTechnology 16:66-70.

Yuan, R. and D.W. Greene. 2000. Benzyladenine as a chemical thinner for 'McIntosh' apples. I. Fruit thinning effects and associated relationships with photosynthesis, assimilate translocation, and nonstructural carbohydrates. J. Amer. Soc. Hort. Sci. 125:169-176. 